\title{
Correspondence
}

https://doi.org/10.11646/megataxa.1.1.9

\section{Major issues facing taxonomy-a personal perspective}

\author{
PAT HUTCHINGS 1,2 \\ '.Australian Museum, Sydney $\triangleq "$ Pat.Hutchings@austmus.gov.au $\odot$ https://orcid.org/0000-0001-7521-3930 \\ ${ }^{2}$ Department of Biological Sciences, Macquarie University, North Ryde 2109, Australia
}

As a taxonomist who has spent her entire working life in one institution and is continuing taxonomic research in retirement, supervising students, and acting as an editor of Zootaxa for polychaetes, obviously, I have strong views on the role of taxonomy and its importance. While there are many issues confronting taxonomy and its role as a science in the 21 st Century, I have selected the three issues I consider most important. I should also like to stress this is an opinion piece based on my perceptions of the current issues facing taxonomists in Australia and in the future I hope to prepare a more detailed manuscript with data to support my comments.

The three issues I have chosen are:

1. Developing stable career paths in which early career taxonomic researchers can see a future, for themselves and taxonomy as a science; achieving this goal requires successional planning and a commitment to taxonomic research by universities, museums, and herbariums, as well as biosecurity, agriculture and forestry, pharmaceutical companies, and other disciplines dependent upon accurate and repeatable taxonomic research.

2. The need for taxonomists to interact with the wider scientific community, governments, and lay people to explain the importance of taxonomy to the economy and its central role in resource management and biodiversity conservation.

3. The importance of mentoring of young students by established workers and recently retired fellows.

In the following, I discuss each of these issues and suggest ways in which they can be addressed.

1. Students need to see a future for taxonomic studies and how their other interests can be combined with taxonomy. For example, how climate change is impacting species distributions or how molecular biology can be used to help in defining species and facilitating our understanding of evolutionary biology. Others more interested in say more applied disciplines such as environmental impact assessments will realise the importance of being able to actually correctly and consistently identity their fauna and similarly for those interested in invasive species.

This concept that taxonomy needs to embrace new techniques or answer specific questions is important when they are proposing topics for their research. Supervisors should also be aware of funding opportunities and future employment when taking on students for higher degrees in taxonomy. Today, students need to ensure they learn the necessary morphological and molecular skills to work on the group which interests them. They must also explore the biology, distribution, physiology etc., of the group which interests them. I would even go so far as to say to pick a group which has some economic or ecological significance as this will make seeking funds much easier if one can explain why it is important to document their biodiversity. In my case, I always have to explain the role which polychaetes play in the benthic ecosystem including their importance in the marine food chain. This is because polychaetes are really not well known even within the scientific community let alone in government agencies. However saying that if you have a student with a passion for the taxonomy of a smaller group let them go for it but really encourage them to expand their thesis to include ecological data and develop as much international collaboration as possible to improve their chances of obtaining a post after completion of their thesis.

Achieving stable career paths needs to be a multipronged approach, and must start at the universities where teachers and those developing curricula must be able to recognize that positions are available for taxonomists across a wide range of areas such as museums, and herbariums, as well as in biosecurity, agriculture and forestry, pharmaceutical companies and consulting companies. Currently when trying to examine the biological courses being offered by universities it is apparent that little whole animal biology is being taught (Hutchings 2013 and I see little evidence this has changed since) and invertebrates are poorly represented. So suggestions as to how to encourage universities to run courses looking at diversity, 
evolution within the Animal Kingdom, could include guest lectures from employed taxonomists explaining job opportunities, or lectures from co- funded positions between Universities and Museums as currently in place at James Cook University and Queensland University with Queensland Museum and University of New South Wales and Australian Museum. Concurrent with this is the need for museums and herbariums to develop and implement successional planning as the current taxonomists retire (Hutchings 2012).

We need to have dedicated taxonomic postdoctoral fellowships Federally funded to be taken up at museums and herbariums run through ABRS, for say 5 years and with a high probability that recipients will then become employed by that organization. This has some political complications as it requires co-operation between State and Federal agencies, but museums and herbariums already are awarded ABRS grants, so possible. This is not a new idea but was proposed back in 2003 (FASTS 2003) as it was seen as a loss of skills, but certainly has not been taken up.

We need to increase funding available for ABRS which is the only dedicated funding agency for biodiversity studies, but the reality of that happening in the current political scene in Australia is poor.

2. Taxonomists need to be far more active in interacting with the rest of the scientific community and really continue to explain that taxonomy is an important discipline which is continuing to evolve as more information and new techniques are incorporated into our discipline. Again this needs to be broken down into various components.

a. Citatation of papers. The publish or perish syndrome is alive and well, together with the citation index of the chosen journal as administrators like to summarise the value of a researcher not only by their number of papers but by their ranking. Checking out the ranking of those journals which publish taxonomic papers using ScimagoJR, reveals that they are only modestly cited and two journals of museums in Australia are not even listed. Zootaxa for example had an impact factor of 0.990 in 2018, whereas a journal like Ecology has an IF of 4.285 in 2019. This means when administrators rank staff in their Departments, taxonomists will always be towards the bottom. This has ramifications as Departments are constantly being assessed based on these rankings so the likelihood of appointing a taxonomist is poor, unless that taxonomist also publishes eg. phylogenetic studies, ecological studies in high profile journals.

So we taxonomists have major problem here, because often while our fellow scientific colleagues use our papers to identify their biota say in their ecological, physiological papers etc, they do not cite them which is called "traditional non-citing" in MacRoberts \& MacRoberts (2010). One solution here is to ensure if you identify the biota for your colleagues make sure you become an author in their papers.

b. Interacting with governments. We taxonomists need to explain to managers within government departments the central role of taxonomy in resource management and biodiversity conservation. For example, developing zoning plans for marine parks needs to include all components of the system such as the benthos and not just the fish and some commercially important crustaceans. This must include the major components such as the diverse and abundant polychaete communities. Most taxonomists almost by default not only can identify their group but they have a vast knowledge re their biology, habits etc., which they can bring to the table when commenting on or developing such zoning plans. Similarly, when working on marine pests, the taxonomist will be able to comment on likely reproductive patterns, habitat requirements which can help in managing such invasions as well as initially confirming that they are an introduced species and not an undescribed native one. But we need to ensure that we are included in such deliberations and in the listing of invasive species.

c. Interacting with the wider community. We taxonomists need to better interact with members of the community for example explaining why coastal wetlands are important and their diverse biota. This may involve talks, leading field trips into the mangroves and seagrass beds and illustrating the animals and explaining what they do and how important to know which animals are actually there and what they are called. As well as discussing the impacts of loss of these habitats.

An important current issue here in NSW is the widespread clearing of native vegetation as a result of loosening of regulations allowing land owners to clear without permits. This increased rate of clearing has increased soil erosion, exacerbated loss of soil water and together with the ongoing drought has made the situation far worse than if that native vegetation had not been cleared in the first place. Those managers need to better interact with the ecologist and the taxonomists to understand the consequences of this loss of vegetation and the associated fauna so they can better communicate not only with the land owners but the politicians which enact the laws.

So we taxonomists need to become better skilled at communicating our discipline and need to use a variety of media. We need to make our data more available not just in monographs but in interactive keys, using social media, writing blogs etc. Towards this I am co-ordinating 
a symposium at the next joint AMSA/NZMSS 2020 to be held in Sydney in July 2020, where we will be inviting not only taxonomists but a range of people who use our data like ecologists, molecular biologists, physiologists, consultants, managers and biosecurity to talk about their projects and how we can all work together better and facilitate transfer of knowledge. We will certainly be inviting people at various stages in their career. The main take home message will be to stress the importance of ensuring that the biota is correctly identified and vouchers deposited where necessary. We hope this will encourage much better communication between taxonomists and all end users of our data and enhance ongoing collaborative programs. We will stress too that the study of Australia's biodiversity is still a work in progress especially amongst the invertebrates.

3. Practicing taxonomists have a responsibility to mentor the next generation of taxonomists.

I firmly believe that we practicing taxonomists have a very important role in mentoring the next generation of taxonomists. As early career researchers begin to work in the field, they need support and encouragement, help in writing grant proposals. You can provide support by introducing them to your contacts not just in the field but also to your contacts in government agencies and universities. While this can be time consuming it is also very beneficial to both sides. I know I have learnt so much from my numerous students and early career researchers and in many cases have developed long lasting collaborative research programs.

So in summary we need to be far proactive in promoting taxonomy, numerous targeted programs (FASTS 2003, National Marine Science Plan, 2015) have not achieved an increase in the number of taxonomists or funding but hopefully the Decadal Plan 2018 will do (Decadal Plan Working Group 2018). This means we must really rethink our strategies and really promote taxonomy as an important discipline and become far more involved in the scientific community and with the users of taxonomy.

\section{Acknowledgements}

I would like to thank my colleagues Harry Recher and Mike Calver for help in getting my thoughts together, although the comments are mine.

\section{References}

Decadal Plan Working Group (2018) A Decadal plan for taxonomy and biosystematics in Australia and New Zealand 20182027. Australian Academy of Science and Royal Society Te Apârangi, Canberra and Wellington, 63 pp. Available from: https://www.science.org.au/files/userfiles/support/reportsand-plans/2018/taxonomy-decadal-plan-hi-res-v200618.pdf (Accessed 24 Dec. 2019)

AMSA/NZMSS (2020) Marine Science in the Anthropocene. Available from: https://www.amsa.asn.au/2020-sydney (Accessed 9 Dec 2019)

FASTS (2003) Proceedings of the National Taxonomy Workshop, Federation of Australian Scientific and Technological Societies. 64 pp. Available from: http://www.environment. gov.au/system/files/pages/9ed0bbbf-713c-4959-8d766fafaeeb18d8/files/ntf-proceedings.pdf (Accessed 24 Dec. 2019)

Hutchings, P.A. (2012) 'The chill winds of climate change freeze funding for biodiversity's critical infrastructure- a personal view. Banks, P., Lunney, D. \& Dickman, C. (eds) Science under siege: zoology under threat'. Royal Zoological Society of New South Wales, Mosman, NSW, pp. 9-12.

Hutchings, P. (2013) 'Why are taxonomists often regarded as second class citizens? a misclassification that threatens the basic infrastructure of biodiversity'. Lunney, D. Hutchings, P. \& Recher, H.F. (eds). Grumpy Scientists: the Ecological Conscience of a Nation. Royal Zoological Society of New South Wales, Mosman, NSW, pp. 26-30.

MacRoberts, M.H. \& MacRoberts, B.R. (2010) Problems of citation analysis: A study of uncited and seldom-cited influences. Journal of the American Society for Information Science and Technology, 61, 1-12.

https://doi.org/10.1002/asi.21228

National Marine Science Plan (2015) White paper submission on Aspects of classifying, cataloguing, curating and systematics of marine biodiversity. Co-ordinator Pat Hutchings. Available from: https://www.marinescience.net. au/nationalmarinescienceplan (last accessed 9 Dec 2019). 